\title{
LA MEMORIA COMO BOOMERANG ¿QUÉ QUEDA DEL CORDOBAZO?
}

\author{
THE MEMORY AS BOOMERANG. WHAT REMAINS OF CORDOBAZO?
}

\author{
ALICIA SERVETTOO (CEA-FCS/FCC/UNC) \\ Centro de Estudios Avanzados de la Facultad de Ciencias Sociales \\ Facultad de Ciencias de la Comunicación \\ Universidad Nacional de Córdoba \\ aliciaservetto@gmail.com
}

\section{LAURA ORTIZ (CEA-FCS/FFyH/UNC)}

Centro de Estudios Avanzados de la Facultad de Ciencias Sociales

Facultad de Filosofía y Humanidades

Universidad Nacional de Córdoba

malauraortiz@gmail.com

\section{Resumen:}

La conmemoración de los 50 años del Cordobazo es una oportunidad para revisar su historia, las condiciones que lo hicieron posible y las consecuencias que produjo. También es una ocasión para examinar la(s) memoria(s), debatir sobre sus significados en el presente y ensayar respuestas a la no siempre cómoda pregunta acerca de ¿Qué queda del Cordobazo?

Como volverse sobre un espejo roto, la pregunta despliega antiguas cuestiones revisadas con lecturas actuales, y nuevos interrogantes que abren viejas discusiones: ¿ंFue el Cordobazo una respuesta del movimiento obrero a la política económica de Krieger Vasena que atentaba contra los salarios y condiciones laborales? ¿Fue el Cordobazo la culminación de una etapa de luchas y resistencia iniciada en 1955? o ¿Fue el inicio de un nuevo ciclo marcado por la politización y la radicalización ideológica?, ¿Se trató de una gesta sólo de hombres?, ¿Resultaba una novedad el activismo y la participación de los estudiantes y los jóvenes?

Desandar cada una de estas preguntas nos obliga a pensar críticamente el pasado, sin caer en la tentación solo de rememorar o, en su defecto, de hacer de aquel acontecimiento un mito de la gesta popular. Por el contrario, se trata de actualizar y analizar ese pasado que vuelve y nos interpela con preguntas, con paradojas y con contradicciones.

\section{Palabras clave:}

Historia Reciente - Cordobazo - Memorias - Protagonistas - Conflictos

\begin{abstract}
:
The commemoration of the Cordobazo's 50th years is an opportunity to review its history, the conditions that made it possible and the consequences that produced. It's also an occasion to examine the memories, discuss their meanings in the present and rehearse answers to the uncomfortable question about what is left of the Cordobazo?

Like go back over a broken mirror, the question unfolds old revised issues with current readings, and new questions that open old discussions: Was the Cordobazo a response of the labor movement to the economic policy of Krieger Vasena that violated wages and working conditions? Was the Cordobazo the culmination of a stage of struggle and resistance begun in 1955? Or it was the beginning of a new cycle marked by politicization and ideological radicalization? Was it a deed only of men? Was the activism and participation of students and young people a novelty?

Returning to each of these questions forces us to think critically about the past and not just remember or make that event a myth of the popular deed. On the contrary, it is about updating
\end{abstract}


and analyzing that past that comes back and challenges us with questions, paradoxes and contradictions.

\section{Keywords:}

Recent history - Cordobazo - Memories - Protagonist Conflicts

Recibido: 16/10/2019 - Aceptado: 18/11/2019 


\section{LA MEMORIA COMO BOOMERANG ¿QUÉ QUEDA DEL CORDOBAZO?}

ALICIA SERVETTO (CEA-FCS / FCC / UNC)

aliciaservetto@gmail.com
LAURA ORTIZ (FFyH / CEA-FCS / UNC)

malauraortiz@gmail.com

\section{Introducción}

La conmemoración de los 50 años del Cordobazo es una oportunidad para revisar su historia, las condiciones que lo hicieron posible y las consecuencias que produjo. También es una ocasión para revisar la(s) memoria(s), debatir sobre sus significados en el presente y ensayar respuestas a la no siempre cómoda pregunta acerca de ¿Qué queda del Cordobazo?

Como volverse sobre un espejo roto, la pregunta despliega antiguas cuestiones revisadas con lecturas actuales, y nuevos interrogantes que abren viejas discusiones. Son recurrentes las presuntas acerca de ¿qué pasó?, ¿por qué pasó lo que pasó? y ¿qué significado tiene aquello para el presente? Esta última pregunta es la más frecuente, la más insistente y, por qué no, la más difícil de responder: ¿Qué queda hoy? ¿Qué significa hoy? Ciertamente, el mismo interrogante tiene implícito la duda, ya que da a entender que de aquello que sucedió y de lo que significó no queda tanto, o al menos, no se puede dar una respuesta lineal.

El Cordobazo es revisado, reinterpretado, resignificado, porque lo que está en juego son los sentidos que ese pasado tiene en el presente y también los sentidos que ese pasado tuvo y tiene para los actores que en ese momento histórico estuvieron involucrados. Al recorrer con mirada atenta, como si se tratara de un boomerang sobre un rollo de película, que nos transporta del presente al pasado y del pasado al presente, nos ubica en un tiempo de notable potencialidad, donde se condensan múltiples combinaciones políticas, sociales y culturales que pueden entrar en disputa. Porque la memoria colectiva es eso, un espacio de polifonías pero también de conflicto por la representación dominante de ese pasado.

Aparecen viejas preguntas con lecturas nuevas, y nuevos interrogantes que abren antiguas discusiones: ¿Fue el Cordobazo una respuesta del movimiento obrero a la política económica de Krieger Vasena que atentaba contra los salarios y condiciones laborales? ¿ $\mathrm{O}$ fue la condensación de un descontento generalizado contra la dictadura de Onganía? ¿Fue el Cordobąo la culminación de una etapa de luchas y resistencia iniciada en 1955 o se trató del inicio de un nuevo ciclo marcado por la politización y la radicalización ideológica? ¿Se trató de una gesta sólo de hombres? ¿Resultaba una novedad el activismo y la participación de los estudiantes y los jóvenes?

Desandar cada una de estas preguntas nos obliga a pensar críticamente el pasado, sin caer en la tentación solo de rememorar o, en su defecto, de hacer de aquel acontecimiento un mito de la gesta popular. Por el contrario, se trata de actualizar y analizar ese pasado que vuelve y nos interpela con preguntas, con paradojas y con contradicciones. 


\section{El mayo cordobés y las revueltas populares}

Abel Bohoslavsky, integrante del PRT-ERP, recuerda:

"La potencia de la irrupción del movimiento obrero en ese mayo cordobés, abrió una época de auge que, a la vez que jaqueó al sistema, dio inicio a una incesante búsqueda de rumbos, y motivó la irrupción de una pléyade de activistas, militantes y organizaciones. Una revolución en las ideas, un sacudón al conformismo político. ¿Era posible una revolución social? ¿Cuál debía ser la estrategia, cuáles las herramientas? Era la época de la naciente Revolución Cubana que mostraba que el socialismo era posible, del Vietnam heroico que enseñaba que el imperialismo no es indoblegable. El Cordobaz̧o no fue propiamente una insurrección -aunque se pareció por sus formas- porque no se planteó como objetivo la conquista del poder, pero su potencia provocó el repliegue de la dictadura. Abrió una época que bien podemos denominar como la de la revolución proletaria, que quedó inconclusa, interrumpida, cuando ese auge ascendente tuvo como respuestas más violentas aún: el terrorismo estatal".

De acuerdo a este testimonio, el Cordobą̧o fue el comienzo de la revolución proletaria, haciendo emerger un nuevo actor, como fueron las organizaciones de izquierda. En cambio para otros protagonistas, como por ejemplo para Elpidio Torres² el estallido de mayo de 1969 fue la culminación de una etapa anterior de lucha del movimiento obrero, que revelaba su fuerza y su conciencia. Dos ejemplos tangibles de cómo se interpreta el significado histórico del Cordobąo.

Ciertamente, aquella rebelión sumó algo a una historia que ya tenía dos elementos intrínsecamente conflictivos: la resistencia del peronismo proscripto, establecido en $1955 \mathrm{y}$, la dictadura del gobierno de la Revolución Argentina instalado con el golpe de estado de 1966. Mientras el primer elemento polarizó el campo político zanjando profundamente la división entre peronistas y antiperonistas, la política económica de Onganía y de su ministro de economía, Krieger Vasena, agudizó las contradicciones sociales y económicas de la clase media y de los sectores populares afectados por la aplicación de medidas que beneficiaban a los sectores capitalistas más concentrados.

Pero también el Cordobazo, abrió varios procesos: liquidación de la dictadura, inauguración de una ola de movilización social, surgimiento de un sindicalismo alternativo - el clasismo-, ${ }^{3}$ desarrollo de las organizaciones revolucionarias, acompañado de un proceso de radicalización política e ideológica de vastos sectores de la sociedad argentina. A partir de mayo del '69 varias agrupaciones comenzaron a plantear que la revolución era posible.

La conflictividad era resultado de una crisis de la dominación social y de un orden político incapaz de contener y regular los conflictos. En este sentido, resulta explicativa la afirmación de Juan Carlos Torre cuando sostiene que "los conflictos en el plano político derivados de la dificultad para encapsular la cuestión peronista, se prolongaron en el plano social en la pugna distributiva en el contexto de detención del crecimiento. Forma parte de la historia que convergió en el Cordobazo". ${ }^{4}$

\footnotetext{
1 Testimonio publicado por Bohoslavky, Abel, "El mayo cordobés, antes y después", Nodal. Noticias de América Latina y el Caribe, en línea en: https://www.nodal.am/2019/05/el-mayo-cordobes-antes-y-despues-por-abel-bohoslavsky/, consulta: 24/5/2019. Abel Bohoslavsky en 1969 era estudiante de $5^{\circ}$ año de Medicina y en los años siguientes fue médico del Hospital Rawson y del Sindicato de Trabajadores de Perkins en Córdoba. Autor de Los Cheguevaristas. La Estrella Roja, del Cordobazo a la Revolución Sandinista, Buenos Aires, Imago Mundi, 2016.

2 Elpidio Torres, dirigente del SMATA, de filiación peronista, vinculado a la CGT-Azopardo, fue uno de los protagonistas de las jornadas del mayo cordobés.

3 Sobre el clasismo, vid. Ortiz, María Laura, Con los vientos del Cordobazo. Los trabajadores clasistas en tiempos de violencia y represión, Córdoba, Editorial UNC, 2019.

4 Torre, Juan Carlos, “A partir del Cordobazo”, Estudios, núm. 4, Córdoba, CEA-UNC, 1994, págs.19 y 20.
} 
Específicamente en Argentina, la etapa que se abrió con el golpe de estado de 1955 que derrocó al presidente Juan Domingo Perón estuvo determinada por la inestabilidad político-institucional que provocaron los sucesivos golpes militares desde 1955 y la ilegitimidad de los gobiernos democráticos que sostuvieron y avalaron la proscripción del partido mayoritario, el peronismo, en el marco de las cíclicas crisis económicas. La dictadura encabezada por el general Juan Carlos Onganía en 1966 fue un proyecto de la clase dominante que pretendió resolver por la vía autoritaria el estado activo y autónomo de los sectores populares. ${ }^{5}$

La política de desmovilización y despolitización llevó, por el contrario, a una mayor conflictividad política y social. En términos de M. Cristina Tortti, en los años previos y posteriores al Cordobazo fueron emergiendo una serie de rasgos nuevos en la relación entre lucha social y lucha política, dando lugar a la emergencia de movimientos populares de tipo insurreccional, al surgimiento de direcciones "clasistas" en el movimiento obrero y al crecimiento de diferentes grupos provenientes del peronismo, de la izquierda, del nacionalismo y de sectores católicos ligados a la teología de la liberación. ${ }^{6}$ Pese a la diversidad de los orígenes políticos, la convicción común a todos ellos era que el sistema de dominación vigente reposaba en la violencia y que sólo otra violencia, que echara a andar una guerra, que debía evolucionar como guerra popular, podría desenmascarar y, finalmente, derrotar a ese sistema que explotaba y oprimía a los pueblos.

A partir de estas lecturas, retomamos entonces las preguntas del inicio: ¿Fue el Cordobazo el final de una historia de resistencia y de luchas obreras sostenida desde la caída de Perón y el golpe militar de 1955, que nutrieron una cultura de la resistencia antidictatorial? ¿Fue el punto de partida de un proceso de movilización social y radicalización política que permitieron formular alternativas anticapitalistas? En otras palabras: ¿Fue la consumación de las luchas peronistas o el inicio de las luchas de la izquierda radicalizada? Si la respuesta se concentra en la primera pregunta, el peso de la historia recae en el movimiento obrero organizado de Córdoba; si la respuesta recae en la segunda, la historia se balancea hacia la izquierda maximalista, dando potencia a un nuevo actor como fue la juventud radicalizada. Ciertamente, estamos frente a un terreno de disputa que no sólo tiene un continum pasado-presente, sino que, además, confluye e influye en la constelación política actual de los actores.

Si consideramos al Cordobaz̧o como uno más en el ciclo de azos que sucedieron en esos años en distintas ciudades argentinas, su peso específico parece perderse. Conocidas como las puebladas en Argentina, se produjo una serie de insurrecciones populares en varias ciudades. Las principales sucedieron entre 1969 y 1972: el Ocampazo (Villa Ocampo, Santa Fe enero-abril de 1969, huelga obrera en torno al ingenio Arno), el Correntinazo (mayo de 1969), el primer Rosariazo (mayo de 1969), el Salteñazo (mayo de 1969), el primer Cordobazo (mayo de 1969), el primer Tucumanazo (mayo de 1969), el segundo Rosariazo (septiembre de 1969), el Choconazo (febrero-marzo 1970), el segundo Tucumanazo (noviembre de 1970), el Catamarqueñazo (noviembre de 1970), el segundo Cordobazo o Viborazo (marzo de 1971), el Casildazo (marzo de 1971), el Jujeñazo (abril de 1971), el Rawsonazo (marzo de 1972), el Mendozazo (abril de 1972), el Quintazo (en la quinta agronómica de la Univ. de Tucumán, junio de 1972), el Rocaz̨o (julio de 1972), el Animanazo (Animaná, Salta, julio de 1972) y el Trelewazo (octubre de 1972). A pesar de que en ellos son muy evidentes sus diferencias, tanto por los objetivos como por los principales protagonistas en las manifestaciones

5 Vid. O’Donnell, Guillermo, El Estado Burocrático-Autoritario, Buenos Aires, Editorial Belgrano, 1982.

6 Tortti, María Cristina, "La Nueva Izquierda en la Historia Reciente de la Argentina”, Cuestiones de Sociología, núm. 3 , Universidad Nacional de La Plata, Facultad de Humanidades y Ciencias de la Educación, Departamento de Sociología, 2006, págs. 19-32.

7 Servetto, Alicia y Noguera, Ana, "De «guerrilleros y subversivos». Hacia un perfil de los y las militantes de las organizaciones revolucionarias armadas de Córdoba", en Carol Solis, Ana y Ponza, Pablo (comps.), Córdoba a 40 años del Golpe: estudios de la dictadura en clave local, Córdoba, Universidad Nacional de Córdoba, 2016, págs. 10-28, en línea en: $\quad$ https://ffyh.unc.edu.ar/editorial/wpcontent/uploads/sites/5/2013/05/EBOOK 40A\%C3\%91OSGOLPE.pdf consulta: 24/5/2019. 
callejeras, en todos los casos se visibilizó la capacidad de rebelión masiva y pública en aquellos años ${ }^{8}$, que no sólo sucedió en escala nacional sino sobre todo latinoamericana y mundial.

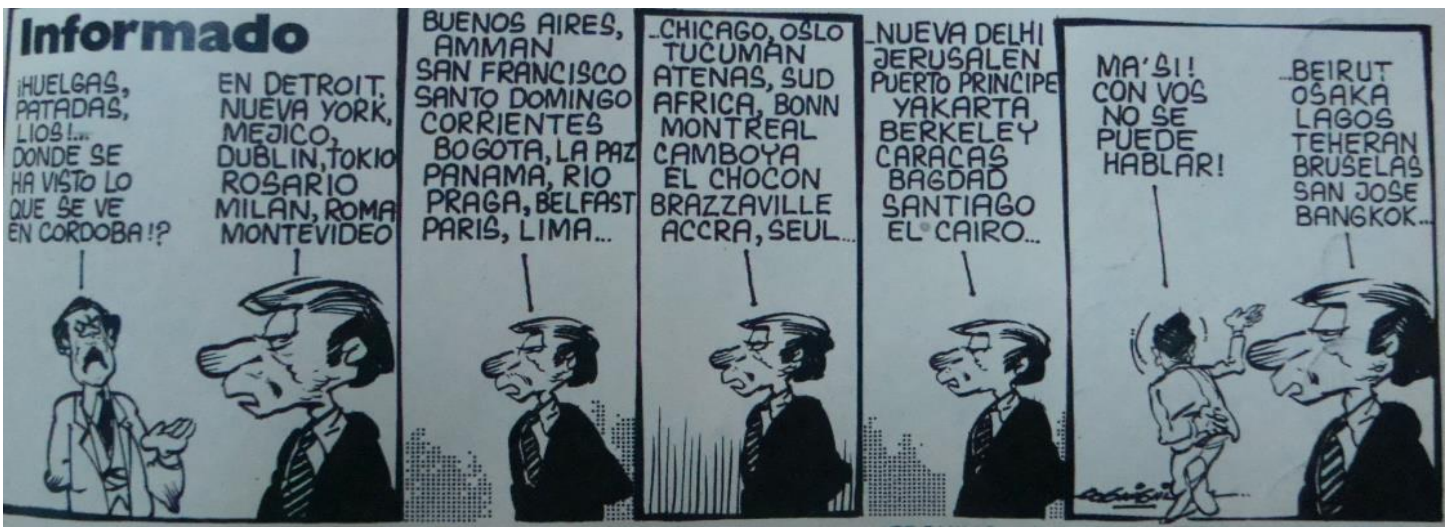

La historieta da cuenta de un proceso de cambio socio-cultural y político que recorrió el mundo. Jerónimo $\mathrm{N}^{\circ} 29$, primera quincena octubre de 1970.

Las revueltas invadieron las calles y recordaron a los gobernantes que la política no podía desplazarse ni con las botas ni con las balas. No obstante fueron las jornadas del mayo cordobés las que irrumpieron con fuerza y se convirtieron en un punto de inflexión para la política argentina, como mito fundante de la lucha política posterior.

\section{Los protagonistas y las memorias del Cordobazo}

Días antes del Cordobazo, el 14/5/1969 se realizó una asamblea en el Club Córdoba Sport, desobedeciendo la prohibición dispuesta por el gobierno provincial. En ella se reunieron unos 5500 obreros mecánicos, que desde 1968 habían iniciado un proceso de movilización muy significativa por conflictos en las fábricas Perdriel y Forja de Renault. ${ }^{9}$ El secretario general del Sindicato de Mecánicos y Afines del Transporte Automotor (SMATA), Elpidio Torres, aprovechó aquella asamblea para denunciar la derogación del sábado inglés y convocó a un paro de 48 hs. a partir del día siguiente. La guardia de caballería de la policía de la provincia reprimió brutalmente a los afiliados que no habían podido entrar. Y luego arrojó gases lacrimógenos al interior del Club, por lo cual los obreros debieron romper los techos de fibrocemento para combatir la acción de los gases. A raíz de estos incidentes la delegación regional Córdoba de la CGT de los Argentinos (CGTA), dio a conocer una declaración:

"Córdoba ha dicho basta a la dictadura, ha dicho basta al atropello, ha dicho basta a la congelación de salarios, a la supresión del sábado inglés, a las quitas zonales, a la derogación de los convenios, a las cesantías, a las persecuciones, a la mordaza política y social". ${ }^{10}$

Decir "basta" era una clara señal de las jornadas que se avecinaban. El movimiento obrero de Córdoba se pronunciaba así enfáticamente contra las medidas que aplicaba la dictadura de Onganía y su proyecto corporativo y neofascista. De hecho, el gobierno había dictado un decreto por el cual derogaba los regímenes especiales sobre el descanso del sábado inglés y había

8 Iñigo Carrera, Nicolás, "Algunos instrumentos para el análisis de las luchas populares en la llamada Historia Reciente”, en López Maya, Margarita, Iñigo Carrera, Nicolás y Calveiro, Pilar (ed.), Luchas contrahegemónicas y cambios políticos recientes en América Latina, Buenos Aires, CLACSO, 2008, págs. 77-94.

9 Ortiz, María Laura, Con los vientos..., op. cit.

10 Declaración de la delegación regional Córdoba de la CGT de los Argentinos, ante el paro del día viernes 16 de mayo. La Voz del Interior, 17/5/1969, pág. 21, citada en Estudios, núm.4, Córdoba, CEA-UNC, 1994, pág. 125. 
anunciado el congelamiento de los convenios colectivos y de los salarios. Esto se agregó a los descuentos zonales, vigentes desde principios de 1969, que permitían a las empresas radicadas en el interior pagar salarios $11 \%$ menos con respecto a los de Buenos Aires. ${ }^{11}$

En respuesta, la dos CGT nacionales decretaron un paro nacional para el día 30 de mayo. En Córdoba, se decidió adelantar un día la jornada de protesta, convocando a un paro activo para el 29/5. En el espacio local, una comisión coordinadora que aglutinaba a los sindicatos afiliados a las dos CGT (Azopardo y De los Argentinos), se encargó de organizar la jornada de protesta. Dirigentes de gremios adscriptos a las distintas centrales obreras encabezaron la organización de la protesta: Elpidio Torres del SMATA, Atilio López de la UTA (Unión Tranviarios Automotor) y Agustín Tosco del Sindicato de Luz y Fuerza.

Durante muchos años, uno de los principales debates en torno al Cordobazo pretendía determinar si el estallido había sido un hecho organizado o espontáneo. En los últimos años, una de las voces más escuchadas en torno a este tema ha sido la de Lucio Garzón Maceda, abogado laboralista que en aquellos años asesoraba al SMATA y la CGT Córdoba. Según sus recuerdos, todo lo sucedido había sido pergeñado por aquellos tres dirigentes sindicales mencionados anteriormente. ${ }^{12}$ Ciertamente, como comentamos al inicio de este apartado, los sindicatos cordobeses tenían en 1969 una experiencia acumulada en sus formas de movilización, que incluía una gimnasia de la resistencia a la represión que el régimen dictatorial venía imponiendo, que incluso puede ampliarse a los gobiernos democráticos y de facto anteriores, si consideramos la "Revolución Libertadora" y el plan CONINTES durante el gobierno de Arturo Frondizi ${ }^{13}$. Sin embargo, es claro que lo que los dirigentes sindicales cordobeses pudieron organizar en torno a las jornadas del 29 y 30 de mayo de 1969 no incluía los sucesos tal cual sucedieron, que estallaron y desbordaron los planes.

Por la mañana de aquel 29 de mayo, obreros y estudiantes salieron unidos a las calles de Córdoba. Varias columnas, desde distintos puntos de la ciudad, siguieron la ruta planificada. Al mediodía, y como resultado del enfrentamiento con la policía, fue asesinado el obrero mecánico Máximo Mena. Este hecho trágico crispó los ánimos y la indignación colectiva precipitó el conflicto y el enfrentamiento. La protesta derivó en una revuelta popular y la población se volcó a las calles. Fue el momento en que los manifestantes le ganaron terreno a la policía, articulando distintos descontentos sectoriales en uno más general. Por la tarde, se declaró el toque de queda y las tropas del ejército se hicieron cargo de controlar la ciudad, a base de gases lacrimógenos, represión y encarcelamiento. Durante la noche, la resistencia se había replegado al Barrio Clínicas, espacio habitado en especial por los estudiantes universitarios. El saldo oficial, según la prensa de la época, fueron 34 muertos, 400 heridos y 2000 detenidos.

Lo que comenzó siendo una protesta obrera, con el apoyo y movilización de los estudiantes, se fue convirtiendo en una revuelta popular e insurrección urbana. Y lo que comenzó siendo una movilización con reivindicaciones sectoriales se fue transformando en una movilización social de ofensiva contra la dictadura. Ello nos invita a reflexionar, en términos conceptuales, en el vínculo entre dirigentes y masas, que es otra vieja discusión en los estudios sobre las organizaciones de trabajadores. ¿Fueron los dirigentes los que planificaron todo? ¿Es posible pensar que tres o cuatro líderes sindicales organizaron el Cordobazo tal cual sucedió? Entonces, ¿cuál es el lugar de las masas: sólo seguir lo que sus dirigentes indicaban o podían tener algún margen más o menos

11 Sobre los acontecimientos del Cordobazo, véase Gordillo, Mónica y Brennan, James, "Protesta obrera, rebelión popular e insurrección urbana en la Argentina: el Cordobazo”, Estudios, núm. 4, Córdoba, CEA-UNC, 1994, págs. $51-74$.

12 Garzón Maceda, Lucio, La CGT Córdoba de La Falda al Cordobazo. Conversaciones de Jorge Oscar Martínez con Lucio Garzón Maceda, Córdoba, UOGC, 2014.

13 Tcach, César, De la Revolución Libertadora al Cordobazo. Córdoba, el rostro anticipado del país, Buenos Aires, Siglo XXI Editores, 2012. 
amplio para expresarse y tomar decisiones? Todo eso remite al viejo debate sobre la estrategia obrera, que en los últimos años se ha revitalizado demostrando que la discusión aún no está clausurada. ${ }^{14}$

Una de las características sobresalientes de las memorias en torno al Cordobazo es su acento épico, relatado como gesta heroica. Las imágenes que se grabaron en la memoria social sobre el hecho lo sostienen: el pueblo logrando que la policía retrocediera, armando barricadas con las herramientas de trabajo cotidiano y echando mano a la vivacidad local. El relato del acontecimiento es de una victoria popular, y quizás esa sea la explicación de su pervivencia en la memoria colectiva, que suele guardar con mayor énfasis aquellos momentos que enaltecen la dignidad $^{15}$. De allí que gran parte de los que recuerdan se reclamen protagonistas principales de la proeza, lo que no quiere decir que estén mintiendo deliberadamente si no que para ellos el hecho tiene una fuerte gravitación en su memoria. Se empoderan en el recuerdo de su participación activa.

Elpidio Torres dirigente del SMATA, de filiación peronista y adscripto a la CGT-Azopardo en aquel entonces, fue uno de los dirigentes en las jornadas del mayo cordobés. En ocasión de la celebración de los 25 años del Cordobazo, Torres reconocía el protagonismo de los trabajadores cordobeses en aquella protesta, posicionándolos como "los únicos" que podían hacer algo en contra de Onganía. Aunque reconoce que estaban acompañados por estudiantes universitarios, el lugar central era el del movimiento obrero, del que él formaba parte.

"Lo primero que quiero señalar es que el Cordobazo fue un hecho muy auténtico, sin especulaciones de ninguna naturaleza, en el cual el movimiento obrero de Córdoba dio una muestra acabada de la grandeza que animaba a los hombres que en ese momento integrábamos sus distintos estamentos. En ese momento existían en Córdoba dos CGT, con diferencia de matices, de ideologías, de procedimiento; pero por encima de esas diferencias existió una coincidencia: la conciencia de que la situación de los trabajadores estaba en peligro, que el país estaba en manos de la dictadura de Onganía y que los únicos que podían realmente hacer algo para demostrar que el país, que el pueblo, vivía y estaba latente, eran los trabajadores. [...] En aquel entonces, quienes jugamos la patriada, quienes salimos a la calle a defender lo que era común a la civilidad, el retorno a la democracia, fuimos los trabajadores acompañados por los estudiantes de la Universidad Nacional de Córdoba. [...]. Pero lo que considero criminal es olvidar esa etapa de lucha porque nos está marcando un derrotero". ${ }^{16}$

En el contexto en que Elpidio Torres realizó esta intervención, su reclamo principal se orientaba a evitar el olvido del Cordobazo, en un contexto donde el neoliberalismo parecía haber triunfado en la derrota de los movimientos revolucionarios de la década de 1960 y 1970 en Argentina. Ciertamente, las operaciones de memoria sobre el pasado dependen de coyunturas favorables o desfavorables para la instalación de una determinada mirada del pasado, que genera condiciones socioculturales de escucha para una interpretación de lo sucedido. Michael Pollak ${ }^{17}$ analiza esos procesos de memoria, reconociendo cómo ciertas verdades se instalan en la memoria colectiva desde el poder y gracias a un ejercicio de violencia simbólica. No necesariamente porque se

14 Varela, Paula e Iñigo Carrera, Nicolás, "Diálogo sobre el concepto de 'estrategia' de la clase obrera”, Archivos de historia del movimiento obrero y la izquierda, Año III, núm.6, 2015, págs. 155-176.

15 Vid. Portelli, Alessandro, "La muerte de Luigi Trastulli (Terni, 17 de marzo de 1949). La memoria y el acontecimiento”, en Historias orales. Narración, imaginación y diálogo, La Plata, Prohistoria ed., 2016, págs. 37-68.

16 Participación de Elpidio Torres en la Mesa Redonda ¿Qué queda del Cordobazo?, organizado por el Centro de Estudios Avanzados de la Universidad Nacional de Córdoba, 20/5/1994. Transcripción en Estudios, núm.4, Córdoba, CEA-UNC, 1994, págs. 36-37.

17 Pollak, Michael, Memoria, olvido, silencio. La producción social de identidades frente a situaciones limite, Buenos Aires, Ediciones Al Margen, 2006. 
construya desde el poder debemos imaginar que la responsabilidad es del Estado, sino que puede referir a los grupos dirigentes de una comunidad de memoria, que puede ser tan amplia como una etnia o tan reducida como una familia. Ese proceso, que Pollak califica como de encuadramiento de la memoria, se produce cuando ciertos acontecimientos e interpretaciones son salvaguardados para reforzar un sentimiento de pertenencia y fronteras sociales entre distintos grupos. En los años 90, los recuerdos del Cordobazo aproximaban la imagen de una sociedad movilizada y defensora de derechos laborales y políticos en un contexto general de desmovilización y despolitización. En esa representación del pasado, la figura de Tosco se constituyó con una centralidad que no tuvieron los otros dirigentes sindicales. Se multiplicaron allí las reproducciones de su imagen en mameluco, referenciando su construcción de líder que nunca se apartó de las bases y, por lo tanto, que discrepaba de los "burócratas". Para Elpidio Torres ese es uno de los tantos mitos sobre el Cordobazo, que se dedicó a discutir con empeño. En sus propias palabras:

“(...) Toda mi vida vestí saco y corbata. Recuerdo a un dirigente del PC (...) que me criticaba diciendo que no podía ser un dirigente obrero vistiendo de saco y corbata. Me mostraba con eso el viejo concepto anarquista o de izquierda muy acendrado, según el cual para ser un buen dirigente había que andar de mameluco, alpargatas y un parche en el trasero.

(...) Tosco era un hombre que vestía igual que yo. En alguna oportunidad, en un abandono que se hizo en el taller al cual pertenecía, el Gringo estando de mameluco, salió a la calle, creo que sin ninguna especulación de su parte. En esa ocasión se tomó la foto que se usó permanentemente.

Pienso que en lugar de alabarlo deforman la realidad, porque no siempre usó el mameluco. Fue el "folclore de izquierda" quien pretendió crear un mito". ${ }^{18}$

Más que mitos proponemos la idea del encuadramiento de la memoria, ciertas versiones de los hechos pasados que se instalan como verdaderas y legítimas en el deber de recordar. No siempre ese proceso de encuadramiento se produce desde arriba hacia abajo, pero sí requiere de agentes de memoria que compartan y reproduzcan ese discurso, como también de objetos de memoria tales como monumentos, museos, etc. En los años 1990, el recuerdo de Tosco y del Cordobazo fue necesario para aquellos sectores de izquierda y progresistas que buscaban alternativas de resistencia al neoliberalismo, empeñado por aquellos años en privatizar las empresas estatales. Entre otras, se intentó privatizar la Empresa Provincial de Energía Eléctrica de Córdoba (EPEC), cuyos trabajadores encuadrados en el Sindicato de Luz y Fuerza abrazaron la tradición tosquista de lucha y lograron evitar la privatización de la empresa.

En aquel contexto, a nadie se le ocurría pensar que Elpidio Torres podría ser un ejemplo para esas nuevas necesidades de resistencia, ya que sobre él la memoria había resguardado la imagen del burócrata, pero no sólo porque le gustara vestir de saco y corbata. La historia de Elpidio Torres quedó anudada a lo que se conoció como la "huelga larga" de SMATA. Aquel conflicto inició con un traslado arbitrario entre plantas de operarios opositores a Torres, justo en el momento previo a las elecciones de delegados. Por la presión de las bases, se decidió emprender una serie de tomas simultáneas de fábricas automotrices justo a un año del Cordobazo, en mayo de 1970. La huelga duró 34 días y al finalizar las patronales despidieron a alrededor de mil trabajadores mecánicos. Elpidio Torres negoció algunas reincorporaciones, pero los trabajadores acusaron que fueron muy selectivas y culparon a su secretario general de "traición" y de aprovechar la oportunidad para "limpiar" de opositores a los cuerpos de delegados y comisiones internas. Además, Torres fue denunciado por los cuerpos orgánicos y agrupaciones opositoras del SMATA que aseguraron que había visitado "domicilios de afiliados aconsejándoles volver al trabajo", desoyendo los mandatos asamblearios de continuar con el paro. Incluso se denunció

18 Torres, Elpidio, El Cordobazo organizado. La historia sin mitos, Córdoba, Editorial Catálogos, 1999, págs. 127-128. 
que la misma dirección sindical "organizó el traslado de la gente de Alta Gracia a Santa Isabel, mediante ómnibus y camiones" "19. Ante el descrédito generalizado, Torres renunció al sindicato y a la CGT, generando el espacio para que la oposición encabezada por René Salamanca pudiera ganar las elecciones sindicales en 1972. En los años de la Dictadura cívico-militar, cuando los sindicatos estaban intervenidos, la figura de Elpidio Torres volvió a aparecer en las negociaciones previas a la normalización sindical, intentando disputar el liderazgo que en ese momento ya ejercía José Campellone. ${ }^{20}$ De allí que su figura se vinculara con la idea del líder alejado de las masas, en contraposición a la figura de Tosco.

Si en 1994 el Cordobazo era un acontecimiento que había que defender para recordar, en cambio en el contexto de una sociedad repolitizada post-2001, la conmemoración se aproxima más a la interpretación que sostienen las políticas de memoria respecto de la historia reciente. Sin embargo, los contenidos instalados en ese deber de recordar, son algo que siempre puede implicar una disputa en el presente. Por ello Pollak asegura que aunque la memoria esté enmarcada y solidificada, puede ser reconfigurada por presiones de otros grupos de memorias, que logran reinventar sus propios relatos del pasado en torno a sus necesidades históricas. Desde esa óptica podemos interpretar la posición actual de la CGT de Córdoba que reclama un relato verdadero, sin mitos, del Cordobazo. Y reivindicar, así, la figura de Elpidio Torres que había sido olvidado por la historia, escrita, según sus palabras, por "los que ganan". Ese pedido se constituyó como una de las novedades de esta $50^{\mathrm{ma}}$ conmemoración de la revuelta, que fue compartida por muchas otras voces de agentes de memoria. De hecho, la figura de Elpidio Torres se revitalizó en gran parte de los discursos e imágenes (murales, pintadas, carteles, etc.) de los 50 años del Cordobaz̧o. Quizás en sintonía con un intento de "peronizar" aquel estallido, esta reivindicación de la memoria diluye una serie de procesos y acontecimientos históricos que explican el porqué de la diferencia en el reconocimiento del protagonismo de unos y otros en el Cordobazo.

\section{El Cordobazo nos parió feministas}

Una cuestión importante para revisar en los relatos hegemónicos es la influencia de los estudios de género para repensar las interpretaciones clásicas del Cordobazo. Hasta hace pocos años, la gesta del 29 de mayo había sido cosa de hombres, y las mujeres quedaron invisibilizadas, no sólo en los relatos masculinos, sino también en las propias reconstrucciones académicas. Sin embargo, su presencia se registra y cobra vida en las voces y testimonios de las mujeres trabajadoras, estudiantes, vecinas que, incluso se las ve, activamente participando, en las imágenes y en los videos de la época.

En relación a esto, el sociólogo Juan Carlos Agulla, en su análisis de los procesos y acontecimientos de mayo de 1969, había señalado una particular apreciación sobre la participación de la mujer universitaria. El autor reconocía que si bien se pudo ver a mujeres al lado de sus compañeros varones, ellas no representaban una gran cantidad: "Dentro de estos acontecimientos, que en Córdoba siempre han tenido características masculinas, ella ha sido la nota de color (a veces, romántica, a veces, grotesca)". Y agregaba que la presencia de las mujeres en las jornadas del Cordobazo fueron un "reflejo", "una maduración", no solo de la composición social de la Universidad de Córdoba -donde se hizo evidente el peso cuantitativo de las mujeres estudiantes-, sino también, de la aparición de la militancia femenina en la vida social y política de

19 Hechos y Protagonistas de las luchas obreras argentinas, Buenos Aires, Editorial Experiencia. Año 1, núm. 1, 1984, pág. 8; La Voz del Interior, 23/07/1970, pág. 30.

20 Ortiz, María Laura, Con los vientos..., op. cit. 
la ciudad, atribuido a la alta presencia de ellas en las facultades más "revoltosas" y "revolucionarias", como las de Filosofía, Arquitectura y Bellas Artes. ${ }^{21}$

En definitiva, lo que Agulla observaba eran las transformaciones que estaba experimentando el mundo laboral, relacionadas al acceso y permanencia de las mujeres. El empleo femenino tenía una gran concentración en las actividades de servicios, docentes, empleadas bancarias y de comercios, secretarias y enfermeras. Dentro del sector industrial, su presencia fue más bien escasa, vinculada mayoritariamente a la industria textil y de confección (calzado y vestido), aunque también ocupaban puestos de trabajo en las industrias de la carne, de la alimentación y del vidrio. En la educación superior también se fue asistiendo a un proceso de creciente feminización. Las estadísticas muestran que, en esos años, había un elevado porcentaje de mujeres en las denominadas "profesiones femeninas" como Letras, Historia, Filosofía, Servicio Social o Psicología. ${ }^{22}$

A pesar de que la presencia femenina en las industrias era minoritaria, apenas un $11 \%$ en $1974^{23}$, la incorporación de las mujeres en los espacios reservados a los varones implicaba además una transformación en las relaciones de género. En sus propias palabras, esas mujeres se daban cuenta que había un mandato cultural que las reservaba a la vida doméstica, pero su decisión era salir a trabajar: "A veces los hombres quieren que te dediques solamente al hogar, pero vos sabés que hay necesidades económicas entonces quiera o no, una sale a trabajar" ${ }^{24}$.

Por el contexto histórico que les tocó vivir, muchas de estas mujeres fueron partícipes de la politización y radicalización de la época y, en algunos casos, se convirtieron en activistas sindicales y militantes. Es decir que fue un momento de ruptura de patrones culturales, donde algunas mujeres no sólo se convirtieron en trabajadoras fabriles sino que, además, se comprometieron con el activismo sindical. Una trabajadora de ILASA explicaba que la actividad sindical era una necesidad para combatir que los patrones las maltrataran: "Todas tenemos ganas de volver a casa temprano, pero a la par de eso sabés que es importante que tenés que hacer tu actividad gremial, porque si te quedás aplastada vienen los de arriba -los patrones- y nos pisotean"25.

21 Agulla, Carlos, Diagnóstico Social de una crisis. Córdoba. Mayo de 1969, Córdoba, Editel, 1969, citado en Servetto, Alicia y Noguera, Ana, "De «guerrilleros y subversivos»..., op. cit.

22 Vid. Noguera, Ana, Revoltosas y revolucionarias. Mujeres y militancia en la Córdoba setentista, Córdoba, Editorial de la Universidad Nacional de Córdoba, 2019.

23 Censo Nacional Económico 1974, Instituto Nacional de Estadísticas y Censos, Dirección de Informática, Estadística y Censos de Córdoba.

24 Entrevistas anónimas a obreras de ILASA, SMATA Córdoba, № 115, 28/11/1973, pp. 3, 7.

25 Entrevistas anónimas a obreras de ILASA, SMATA Córdoba, op. cit. 


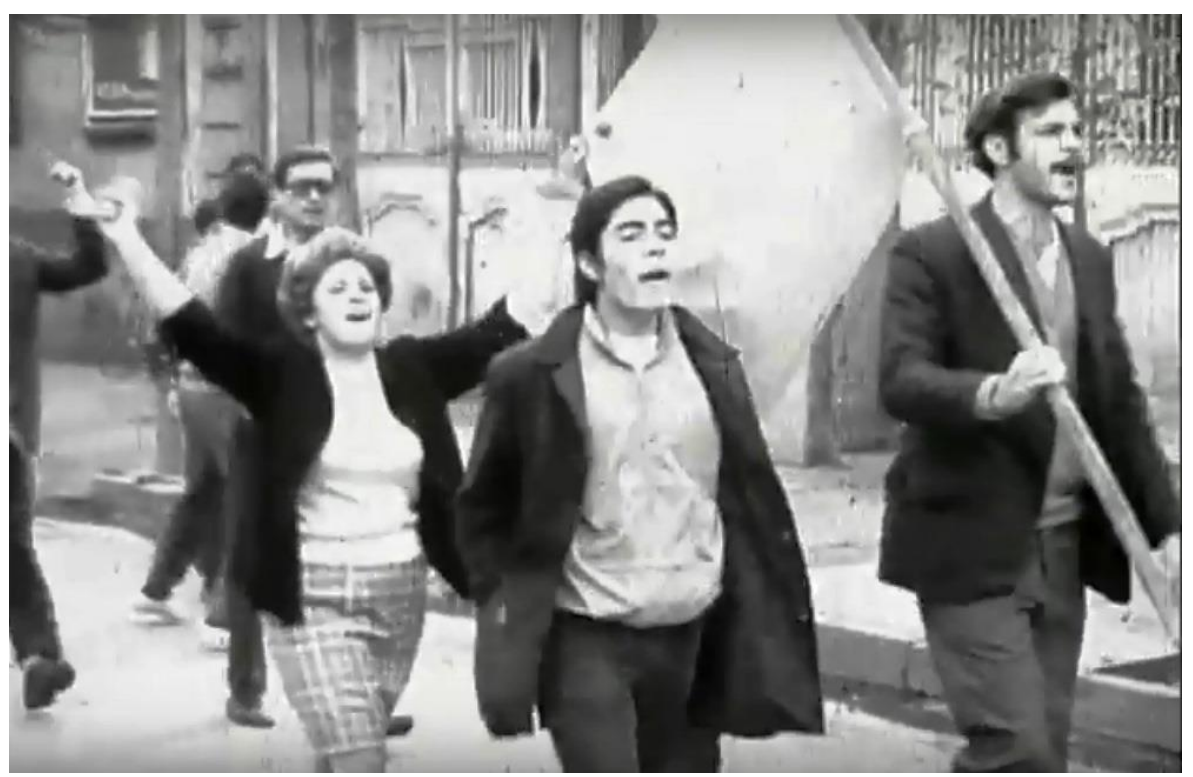

Imagen del Cordobazo. La fotografía retrata a Nené Peña, empleada bancaria, participando de la protesta. Con esta foto luego fue identificada y fue la única mujer juzgada en un Consejo de Guerra por los hechos de mayo de 1969. https://ffyh.unc.edu.ar/alfilo/el-cordobazo-fue-el-bautismo-de-fuego/

Susy Carranza, ex trabajadora de una fábrica de vidrio, recuerda las luchas y las demandas que protagonizaban las mujeres en aquellos años. Así, contaba que en la fábrica de lámparas eléctricas, los hornos de hasta 800 grados les daban a la altura del vientre:

"Se nos cocinaban los ovarios y teníamos menstruaciones muy abundantes, muy dolorosas, con hemorragias. Peleábamos por esas cosas, porque nos quemábamos los dedos, para no tener que comer en el piso o en las piletas frente al baño. La mayoría no había terminado la secundaria y los sindicalistas hombres, que no se inquietaban por estas cosas nuestras, se ocupaban de las cuestiones políticas". ${ }^{26}$

Soledad García, por su parte, hace memoria de lo difícil que era para las mujeres que les dieran lugar para hablar en los actos públicos. "Ellos estaban en la disputa de poder y las mujeres, en mejorar la vida":

"De algún modo -agrega quien fuera dirigente de la UEPC-, los días del Cordobazo nos parieron feministas, aunque no se hablaba de género, sino que nuestras herramientas eran sindicales, sociales, políticas; hablábamos de conciencia de clase". ${ }^{27}$

Lina Averna, operaria de ILASA, evoca con nitidez:

"No usábamos ninguna medida de protección ni el menor equipamiento personal. Nos hacían convenios por separados de los varones y después supimos que no sólo cobraban más, sino que también tenían los puestos más calificados. Me tocó 'hacer la punta' en el abandono de tareas el 29 a las 10.30. Estábamos todas juntas y me acuerdo de la alegría que teníamos. Me animaría a decir que el Cordobazo fue un verdadero bautismo para las que nunca abandonamos la lucha". 28

26 Testimonios citados en Fulchieri, Bibiana, El Cordobazo de las mujeres, Córdoba, Editorial Las Nuestras, 2018, citado en La Voz del Interior, Córdoba, versión on line [https://www.lavoz.com.ar/numero-cero/mujeres-en-elcordobazo-ellas-siempre-estuvieron], consulta: 26/5/2019.

27 Fulchieri, Bibiana, El Cordobazo de las mujeres..., op. cit.

28 Fulchieri, Bibiana, El Cordobazo de las mujeres..., op. cit. 
En efecto, es posible advertir a partir de estos testimonios que lejos de ser una protesta eminentemente masculina, fue visible e importante la presencia de las mujeres. Parafraseando a Ana Noguera, si bien en términos cuantitativos las jornadas de mayo tuvo una "impronta netamente masculina", para las mujeres fue un verdadero acontecimiento "bisagra" o como "un "bautismo de fuego" en términos políticos. ${ }^{29}$ Pero lo más significativo es que, producto de las luchas y de las conquistas vinculadas a las mujeres, hoy, la academia, la prensa, la esfera pública en general, consideran, recuperan y visibilizan la actuación de las mujeres en la historia del país, rompiendo de esta forma el esquema del relato dominante.

\section{La movilización estudiantil}

La participación de los estudiantes en el Cordobazo, responde ciertamente a un proceso que da cuenta de las preocupaciones propias del conflicto estudiantil, de la universidad y de la situación política producida por la dictadura de Onganía. Pero también, la participación estudiantil y su involucramiento en los asuntos públicos, encuentran sus marcas en las consignas de la Reforma del '18. No obstante, lo más novedoso en esta etapa fue la alianza obrero-estudiantil y la convergencia en torno al discurso antidictatorial.

Las medidas represivas del gobierno en las universidades contra los profesores y estudiantes, la intervención y supresión de la autonomía universitaria, la prohibición de las organizaciones político-estudiantiles, más la persecución y la censura fueron factores que condujeron a la reacción y movilización estudiantil. Los discursos antiimperialistas se fueron transformando en discursos anti-capitalistas, y la lucha comenzó a plantearse en términos de revolución.

Pensando desde Córdoba, resulta clave destacar la importancia cuantitativa y cualitativa de los jóvenes universitarios en la ciudad. De hecho, la Universidad de Córdoba actúa aún hoy como polo de atracción de numerosos estudiantes del interior de la provincia, del noroeste e inclusive de Bolivia y Perú. ${ }^{30}$ Por cierto, entre 1966 y 1976, los estudiantes de la Universidad Nacional de Córdoba (UNC) experimentaron el período más tumultuoso de toda su historia. Como señala James Brennan, "la década fue también única en el sentido que el activismo de los estudiantes de la UNC, no constituía solamente un asunto local, sino más bien formaba parte de una movilización mundial de la juventud, particularmente a nivel universitario, aunque siempre llegando más allá de ese ámbito". ${ }^{31}$

Una cuestión a destacar como novedosa es la figura del estudiante - trabajador. Según Francisco Delich $^{32}$, los estudiantes en esa condición constituían un 35\% del total de la población estudiantil, con un aporte clave y significativo por parte de la Universidad Tecnológica de Córdoba. Al respecto, el siguiente testimonio, es ilustrativo de las condiciones de trabajo y estudio de esta franja de estudiantes-trabajadores o de trabajadores-estudiantes:

"Para el Cordobazo yo era obrero y también estudiante universitario en la Facultad de Derecho, ya que quería ser abogado. Era un sacrificio muy grande y recuerdo que tenía que hacer materias libres porque me coincidían los horarios con el trabajo. Leía los apuntes en el baño, lo escondía en el overoll y allí estudiaba". ${ }^{33}$

\footnotetext{
29 Noguera, Ana, Revoltosas y revolucionarias..., op. cit.

30 Crespo, Horacio y Alzogaray, Dardo, "Los estudiantes del mayo cordobés”, Estudios, núm.4, Córdoba, CEAUNC, 1994.

31Brennan, James, "Rebelión y revolución: los estudiantes de la Universidad Nacional de Córdoba en un contexto transnacional", en Saur, Daniel y Servetto, Alicia, Universidad Nacional de Córdoba. Cuatrocientos años de historia, Córdoba, Editorial de la Universidad Nacional de Córdoba, 2013.

32 Delich, Francisco, Crisis y protesta social. Córdoba, mayo de 1969, Córdoba, CEA-UNC, 1994.

33 Testimonio de Humberto Brondo, obrero de IKA y estudiante de Derecho. Entrevista realizada por Mónica Gordillo en diciembre de 1989, publicada en Estudios, núm.4, Córdoba, CEA-UNC, 1994, pág. 186.
} 
Lucía Robledo, militante estudiantil en 1969, refiere a las luchas que emprendían juntos al movimiento obrero.

“A partir del golpe del '66, desde la Universidad resistimos con fuerza al gobierno de Onganía que había echado a muchos de nuestros profesores y anulado nuestra ley universitaria. Hay que recordar que durante todo ese año nos mantuvimos en huelga, sin ir a clases ni rendir exámenes, movilizándonos permanentemente no sólo por nuestra problemática particular sino también tratando de hacer realidad la unión obreroestudiantil". ${ }^{34}$

Pero la lucha estudiantil no se daba solamente en Córdoba y en la UNC. De hecho, el Cordobazo fue precedido por una serie de movilizaciones estudiantiles y obreras cuyos puntos más trágicos fueron las manifestaciones de los estudiantes en Corrientes donde resultó asesinado Juan José Cabral, y en Rosario fueron asesinados los jóvenes Adolfo Bello y Luis Blanco lo que provocó una gran protesta conocida como el primer Rosariazo. También en Salta se produjo una sublevación de estudiantes secundarios en contra del interventor designado por el gobierno de Onganía.

Sin dudas, que este protagonismo estudiantil se enlazaba con el papel de los jóvenes como sujeto colectivo que había cobrado visibilidad significativa desde finales de los años cincuenta. Fue la juventud, en términos de Valeria Manzano, la portadora de las dinámicas de modernización cultural y también de sus descontentos, expresados bajo las formas de rebelión cultural y radicalización política. ${ }^{35}$

Incluso desde las memorias de "del otro lado", el Cordobazo tiene una representación que es interesante atender. En la interpretación del director de inteligencia de Córdoba, el capitán Héctor Vergez -hoy condenado por delitos de lesa humanidad-, el Cordobazo fue uno más en la "ola de vandalismos urbanos al estilo parisino y mexicano", similar al que se vivió en otras ciudades. Sin embargo, sostiene el genocida, el de Córdoba fue especial porque fue exaltado por los "terroristas" ya que se trató del único caso en que "los agitadores -siempre estudiantes- fueron acompañados por obreros «clasistas» de los «gremios combativos», activados por Agustín Tosco y René Salamanca, la cual creó la leyenda, mantenida hasta hoy, de un sostén "popular»" ${ }^{36}$ En esta representación, la leyenda del Cordobazo se circunscribe a su inexistente apoyo popular, producto de la acción de estudiantes agitadores devenidos terroristas. Si bien se trató de una conjunción, de una alianza, de una unidad, el componente obrero en primer lugar otorga una legitimidad a la acción basada en el sustento popular del que el estudiantado universitario pareciera carecer. Todas ellas son construcciones simbólicas elaboradas colectivamente, en un tiempo posterior a los hechos, sobre las que aún quedan muchas reflexiones pendientes.

\section{A modo de cierre}

Las puebladas, las protestas obreras, las luchas estudiantiles, en fin, la conflictividad contenía, en su esencia, un profundo malestar, pero era un malestar social, impregnado de indignación, de furia, de ira, de enojo colectivo, donde se mezclaba la violencia con el entusiasmo. Pero entre todos esos estallidos, el de mayo de 1969 en Córdoba se constituyó en la construcción social de la memoria nacional como un momento especial en el que cristalizaron una serie de cambios políticos y culturales de largo aliento.

34 Entrevista a Lucía Robledo realizada por Beatriz Torres, 1994, citada en Estudios, núm. 4, op. cit, pág. 179.

35 Manzano, Valeria, La era de la juventud en Argentina. Cultura, política y sexualidad desde Perón hasta Videla, Buenos Aires, Fondo de Cultura Económica, 2017.

36 Vergez, Héctor, Yo fui V argas. El antiterrorismo por dentro, Buenos Aires, Edición del autor, 1995, pág. 239. 
Lo cierto es que nada volvió a ser igual. De allí que la expresión con el aumentativo azo sea descriptivo y performativo al mismo tiempo, porque cada uno de esos acontecimientos tuvo, en el escenario político, una fuerza disruptiva. Si el ejercicio de la política estaba clausurado, los canales de representación prohibida, la mediación partidaria anulada, la política resurgió por otro lado, en otros espacios, y las calles se transformaron en el lugar escogido para hacerse escuchar. Desde abajo, comenzó a impugnarse cualquier esquema de poder que los excluyera económicamente, socialmente y políticamente.

La dinámica política comenzó a relacionarse con estas nuevas formas de participación de la sociedad argentina, hipermovilizada y alentada por un imaginario de cambio social. En casi todo el país se instalaron espacios de sociabilidad diferentes de los canales tradicionales de la política pero que a su vez se politizaron intensamente. Prácticamente no hubo sectores que no fueron tocados por la onda expansiva de la politización: sindicatos, estudiantes, vecinos, inquilinos, habitantes de las villas de emergencia, sacerdotes, campesinos, etc. De esta forma, la política se fue articulando con los problemas sociales y económicos de cada una de las realidades locales, y nuevos y viejos actores entraron en la escena política con nuevos repertorios de confrontación que sacudieron los esquemas de poder, e hicieron recordar que la participación política deviene del ejercicio de la soberanía popular.

Sin embargo, los recuerdos de aquellos momentos han ido cambiando de significado a lo largo de estos 50 años. Como un boomerang, la memoria sobre ese pasado se construye desde un presente que necesita relatar(se) para posicionarse en las disputas políticas actuales. ¿Qué queda hoy del Cordobazo? Es una pregunta que nos exige revisitar la historia, de antes y de después. Y encontrar allí, en medio de las luchas, un sentido para el presente que debe ser tanto ejercicio de memoria como una oportunidad para pensar políticamente el futuro. 